\title{
Comparison of the luminescent properties of LuAG:Pr nanopowders, crystals and films using synchrotron radiation
}

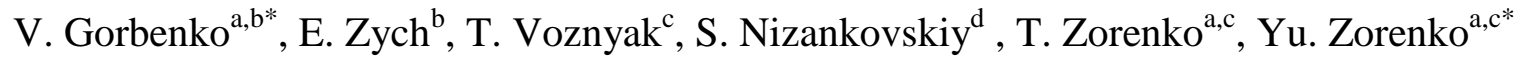 \\ ${ }^{a}$ Institute of Physics, Kazimierz Wielki University in Bydgoszcz, 85090 Bydgoszcz, Poland \\ ${ }^{b}$ Department of Chemistry, Wroclaw University, 50-383 Wroclaw, Poland \\ ${ }^{c}$ Electronics Department, Ivan Franko National University of Lviv, 79017 Lviv, Ukraine \\ ${ }^{d}$ Institute for Single Crystals NAS of Ukraine, 61001 Kharkiv, Ukraine \\ *corresponding authors: Vgorbenko@gmailcom; zorenko@ukw.edu.pl.
}

\begin{abstract}
Comparison of the luminescent properties of nanopowder, single crystal and single crystalline film of $\operatorname{Pr}^{3+}$ doped $\mathrm{Pr}$-doped $\mathrm{Lu}_{3} \mathrm{Al}_{5} \mathrm{O}_{12}$ garnet (LuAG:Pr) prepared by the different technological methods is performed in this work using the time-resolved emission spectroscopy under excitation by synchrotron radiation with an energy of $3.7-25 \mathrm{eV}$ at $300 \mathrm{~K}$ and $10 \mathrm{~K}$. The notable differences in the properties of the $\operatorname{Pr}^{3+}$ luminescence are observed in LuAG:Pr crystals and films caused by involving the $\mathrm{Lu}_{\mathrm{Al}}$ antisite defects and oxygen vacancies in crystals and $\mathrm{Pb}^{2+}$ flux related dopant in films in the excitation processes of the $\mathrm{Pr}^{3+}$ luminescence. At the same time, we have also found that the influence of host defects on the $\operatorname{Pr}^{3+}$ luminescence is significantly smaller in the LuAG:Pr nanopowders.
\end{abstract}

Keywords: nanopowders, single crystals, single crystalline films, $\mathrm{Lu}_{3} \mathrm{Al}_{5} \mathrm{O}_{12}$ garnet, luminescence, $\operatorname{Pr}^{3+}$ dopant

\section{Introduction}

Pr-doped $\mathrm{Lu}_{3} \mathrm{Al}_{5} \mathrm{O}_{12}$ garnet (LuAG:Pr), apart from their applications as scintillators in single crystal (SC) form [1-3], attract also an attention as single crystalline film (SCF) screens for 2D/3D microimaging based on the X-ray or synchrotron (SR) radiation [4] as well as ceramic [5, 6] and nanopowder (NP) phosphors [7, 8]. Properties of these materials in the different crystalline forms are strongly influenced by the differences in the methods and conditions of their preparation.

Meanwhile, substantial differences in the methods and conditions of material preparation from the low-temperature melt-solution (films), high temperature melt (crystals) and solid-state reactions (ceramics) usually result in the significant differences in their luminescent properties. Such differences are caused by the different types and concentrations of intrinsic defects over the main volume and surface of scintillators as well as by interaction of the defects with impurity centers. The contribution of defect centers to the intrinsic luminescence of hosts or the luminescence of dopants in complex oxides can be so significant that it can partly or even completely mask the native luminescent properties of matrix or impurities.

The concentration of vacancies, antisite defects and their aggregates can be strongly reduced the using the solid state reaction (ceramics) or films prepared by low-temperature LPE crystallization from 
the melting fluxes. At the same time, the LPE grown films always contain the components of flux which also can strongly influence their luminescent properties. The luminescent properties inside the nano- and - micro-powders usually differ from the properties of their surfaces and grain borders with substantially larger content of defects.

Therefore, only the detailed comparative investigations of the luminescent properties of the complex oxides, prepared in the different crystalline forms at various conditions of growth, enable to extract the fundamental luminescent properties of their matrix from the background of defect emission as well as to detect the "real picture" of the dopant luminescence in these materials. Using for this purpose the traditional spectral methods and synchrotron radiation excitation with energy in the range of fundamental absorption of the compounds under study opens also a unique possibility for correct comparison of the luminescent properties of these materials in the different crystalline forms. Recently we have performed such comparative study of the luminescence of films and crystals of the known oxide materials - undoped and Ce doped YAG and LuAG garnets [9, 10], YAP and LuAP perovskites [11, 12], YSO and LSO silicates $[13,14]$. In this paper, we try to extend this knowledge to the $\operatorname{Pr}^{3+}$ doped LuAG garnet prepared in the nanopowder, single crystalline film and crystal forms.

The luminescent and scintillation properties of the LuAG:Pr in SC and ceramic states were recently compared using the traditional spectral methods $[1,2,5-8,15,16]$ and synchrotron radiation (SR) excitation [17, 18]. The luminescent and scintillation properties of the LuAG:Pr SCFs have been also investigated by some of us and compared with those of reference SCs using the absorption, cathode- and photoluminescence and light yield (LY) measurements under excitation by $\alpha$-particles [19, 20]. We have found that the emission spectra and decay kinetics of LuAG:Pr SCs and s due to the $5 \mathrm{~d}^{1}$ $4 \mathrm{f}^{2}$ transition of $\mathrm{Pr}^{3+}$ ions are notably different due to: (i) the presence of $\mathrm{Y}_{\mathrm{Al}} / \mathrm{Lu}_{\mathrm{Al}}$ antisite defects as emission centers in UV range and trapping centers as well in the case of SCs, grown from the melt at high temperatures; (ii) the influence of $\mathrm{Pb}^{2+}$ flux related dopants in the case of LuAG:Pr SCF, grown from $\mathrm{PbO}$ based flux at significantly lower temperatures.

The aim of our report is to compare the luminescent properties of LuAG:Pr NPs with respect to their SC and SCF counterparts using SR excitation of the $\operatorname{Pr}^{3+}$ ion luminescence in LuAG host.

\section{Samples and experimental technique}

The NP of LuAG:Pr $(0.1 \%)$ was prepared by the solid state reaction using the Pechini method at temperatures below $1000^{\circ} \mathrm{C}$. The $\mathrm{SC}$ of this garnet was grown by the Horizontal Direct Crystallization (HDC) method under Ar atmosphere at temperatures around $2000^{\circ} \mathrm{C}$ [21]. The LuAG:Pr SCF was crystallized by the liquid phase epitaxy (LPE) method from melt-solutions based on the $\mathrm{PbO}-\mathrm{B}_{2} \mathrm{O}_{2}$ flux in air atmosphere onto YAG substrates at temperatures $960-1020^{\circ} \mathrm{C}$ [19]. For all the mentioned technologies the same row materials of $4 \mathrm{~N}\left(\mathrm{Al}_{2} \mathrm{O}_{3}\right)$ and $5 \mathrm{~N}\left(\mathrm{Lu}_{2} \mathrm{O}_{3}\right.$ and $\left.\mathrm{Pr}_{4} \mathrm{O}_{7}\right)$ purity were used. 
The time-resolved luminescent spectroscopy of LuAG:Pr SC, SCF and NP samples were performed under excitation by SR with an energy in the 3.5-25 eV range at Superlumi station at HASYL$\mathrm{AB}$ at DESY at 10 and $300 \mathrm{~K}$. These energy ranges allow exciting the $\mathrm{Pr}^{3+}$ absorption bands, the exciton range and the range above the onset of interband transitions of LuAG host. The emission and excitation spectra were measured with a monochromator ARC and PMT Hamamatsu R6358P in both the integral regime (1.2-200 ns) and the 1.2-12 ns and 150-200 ns time intervals (fast and slow components, respectively) in the limits of SR pulse with a repetition time of $200 \mathrm{~ns}$. The decay kinetics of the luminescence was measured in the 0-200 ns time range.

\section{Experimental results}

3.1 Luminescence spectra. The luminescence spectra of LuAG:Pr NPs, SCs and SCFs under excitation by SR with different energies at $300 \mathrm{~K}$ and $10 \mathrm{~K}$ are presented in Fig.1a, b; 1c,d and 1e,f, respectively. From comparison of the emission spectra of LuAG:Pr NPs, SCs and SCFs (Fig.1) we have exactly determined the structure of the luminescence bands in the UV and visible ranges, related to the d-f and f-f transitions of $\operatorname{Pr}^{3+}$ ions, respectively, as well as the luminescence bands of defect centers.

The luminescence of LuAG:Pr SCs (Fig1c, 1d) in the UV range is the superposition of the selftrapped exciton (STE) emission in the band peaked at $250 \mathrm{~nm}[9,10]$, the $\mathrm{d}$-f luminescence of $\operatorname{Pr}^{3+}$ ions in the 300-450 nm range $[1,2]$ and the luminescence of antisite defected related centers $[9,10]$. Specifically, the luminescence of antisite defect related centers consists of the emission of excitons
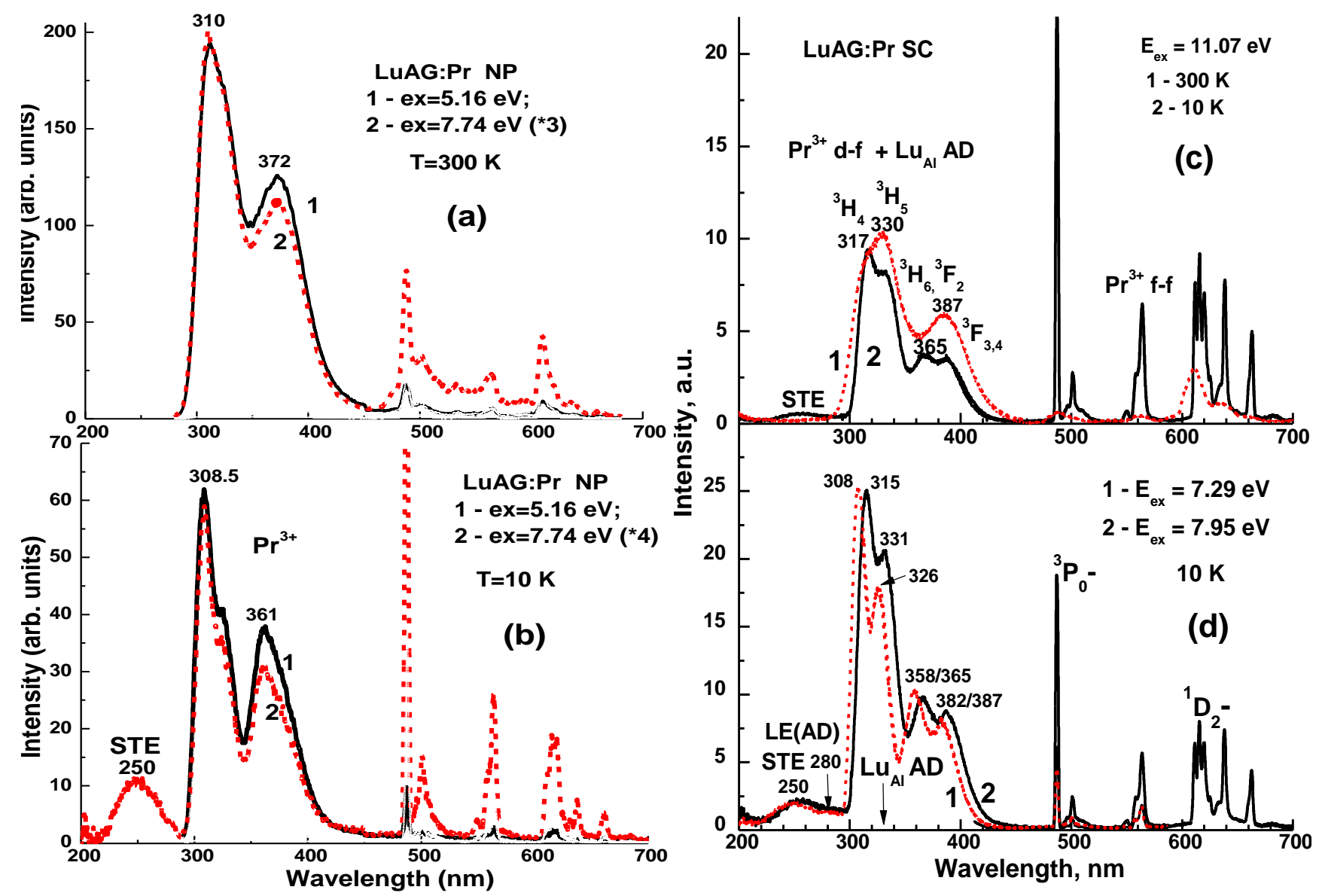


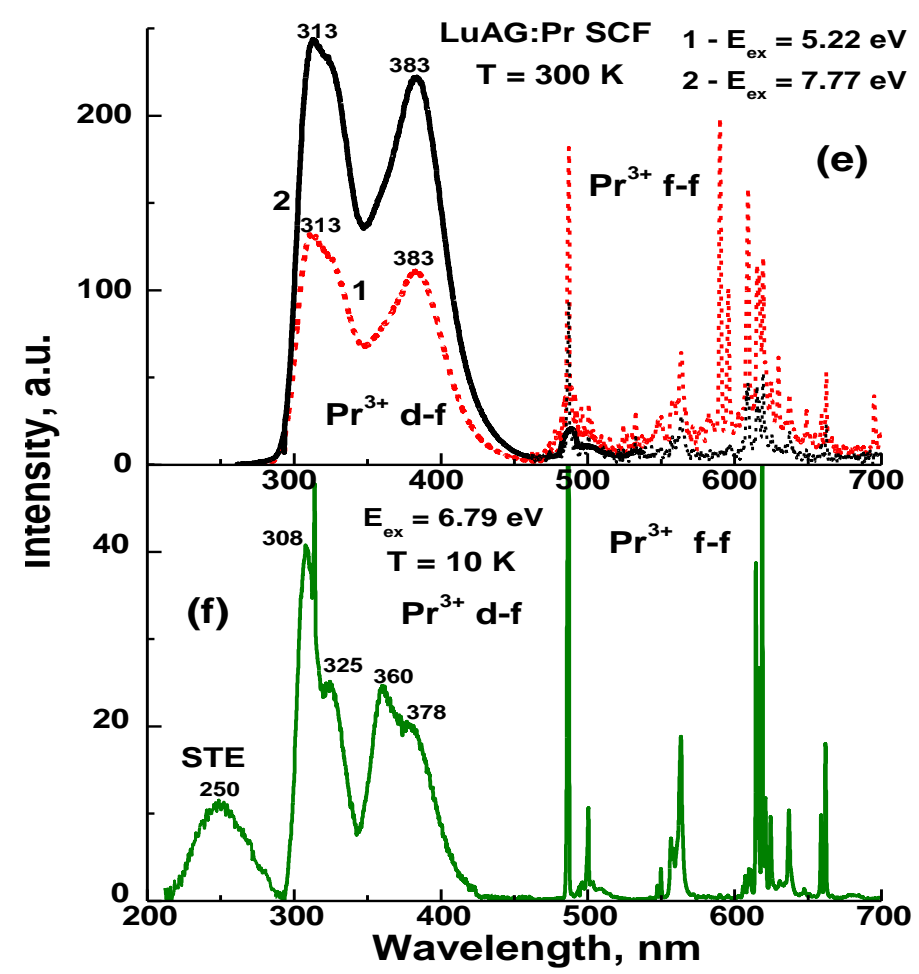

Fig.1. (a, b) - luminescence spectra of LuAG:Pr NP at $10 \mathrm{~K}$ (a) and $300 \mathrm{~K}$ (b) under excitation in the $\operatorname{Pr}^{3+}$ f-d absorption band at $5.16 \mathrm{eV}(1)$ and in the exciton range at $7.74 \mathrm{eV}(2) ;(\mathrm{c}, \mathrm{d})$ - luminescence spectra of LuAG :Pr SC at $300 \mathrm{~K}$ (a) and $10 \mathrm{~K}$ (b) under excitation in the range of interband transitions at $11.07 \mathrm{eV}$ $(\mathrm{c} 1, \mathrm{c} 2)$, at the onset of interband transitions at $7.92 \mathrm{eV}(\mathrm{d} 2)$ and with energy of creation of excitons bound with $\operatorname{Pr}^{3+}$ ions at $7.29 \mathrm{eV}(\mathrm{d} 1)$. (e, f) - luminescence spectra of LuAG:Pr SCF at $300 \mathrm{~K}$ (a) and $10 \mathrm{~K}$ (b) under excitation by SR with energies close in the range of $\operatorname{Pr}^{3+} 4 \mathrm{f} 5 \mathrm{~d}$ transitions (e1) to the onset of interband transitions (e2) and as well as with the energy in the range of creation of excitons bound with $\operatorname{Pr}^{3+}$ ions (f). The positions of STE emission band and the bands related to $\mathrm{Lu}_{\mathrm{Al}}$ ADs are indicated.

localized around $\mathrm{Lu}_{\mathrm{Al}} \mathrm{AD}(\mathrm{LE}(\mathrm{AD})$ centers) in the band peaked at $280 \mathrm{~nm}$ and the luminescence of excitons bound with $\mathrm{Lu}_{\mathrm{Al}}$ in the band peaked approximately at $330 \mathrm{~nm}$ [9] (Fig.1c, curves 1 and 2). The luminescence of the last centers is dominated in the room temperature range under excitation above the LuAG band gap ( $8.15 \mathrm{eV}$ at $8 \mathrm{~K}$ ) and causes the visible shift of emission spectra of LuAG:Pr SCs at 300 $\mathrm{K}$ with respect to the spectra at $10 \mathrm{~K}$ (Fig.1c, curves 2 and 1, respectively). Due to the luminescence of defect $\mathrm{LE}(\mathrm{AD})$ and $\mathrm{Lu}_{\mathrm{Al}} \mathrm{AD}$ centers, the emission spectra of LuAG:Pr SCs do not coincide in the case of excitation with the energies of creation of excitons bound with $\mathrm{Pr}^{3+}$ ions and in the case of excitation in the onset of interband transitions (Fig.1d, curves 1 and 2, respectively).

As opposed to $\mathrm{SCs}$, due to the absence of $\mathrm{Lu}_{\mathrm{Al}} \mathrm{AD}$ as emission centers in low temperature sintering NP and LPE grown SCF samples, the luminescence spectra of LuAG:Pr NPs and SCF counterparts keep well the form and position of $\operatorname{Pr}^{3+}$ related bands at all excitation energies at $300 \mathrm{~K}$ (Fig. 1a and 1e) and $10 \mathrm{~K}$ (Fig.1b and 1f) taking into account the typical temperature shift.

The ratio of the intensity d-f to f-f luminescence in LuAG:Pr NPs depends on the excitation wavelength and temperature (Fig.1 a). It is important to note here that the emission spectra of LuAG:Pr 
NPs under excitation in the $4 \mathrm{f}-5 \mathrm{~d}$ band at $5.16 \mathrm{eV}$ (Fig.1a and 1f, curves 1) show the dominant broad d-f emission in the UV range while at the LuAG host excitation at $7.74 \mathrm{eV}$ these spectra show large contribution of the f-f luminescence in the visible range (Fig.1a and 1b, curves 2). Similar behavior is also observed in LuAG:Pr SC and SCF counterparts (Fig.1d and 1e).

The observed f-f emission in LuAG:Pr can originate from the ${ }^{3} \mathrm{P}_{0}$ level, which under the $4 \mathrm{f}-5 \mathrm{~d}$ excitation can be reached by the $4 \mathrm{f} 5 \mathrm{~d} \rightarrow{ }^{3} \mathrm{P}_{\mathrm{J}}$ and/or ${ }^{1} \mathrm{I}_{6}$ radiative transitions followed by the nonradiative relaxation to ${ }^{3} \mathrm{P}_{0}$ level. In the case of the LuAG host excitation, the energy to the $\mathrm{Pr}^{3+}$ excited levels can be reached also via the excitons states: the self-trapped exciton (STE) states, formed mainly at low temperatures [17, 22], and excitons bound (trapped) with $\operatorname{Pr}^{3+}$ ions at higher temperatures. After formation of these excitonic states, the energy can simultaneously transferred to $5 \mathrm{~d}$ levels and ${ }^{3} \mathrm{P}_{\mathrm{J}}$ or ${ }^{1} \mathrm{I}_{6}$ f-levels of the $\operatorname{Pr}^{3+}$ ions. Recently, the effect dependence of the shape of $\operatorname{Pr}^{3+}$ luminescence spectrum on the excitation wavelength has been discussed in details in the papers [23, 24]. Namely, in these works it has shown that that the intensity of the $\mathrm{d}-\mathrm{f}$ and $\mathrm{f}-\mathrm{f}$ luminescence can be controlled by praseodymium trapped exciton state and this is strongly reflected in the intensity of ${ }^{3} \mathrm{P}_{0}$ and ${ }^{1} \mathrm{D}_{2}$ emission in $\mathrm{LiNbO}_{3}: \operatorname{Pr}, \mathrm{CaWO}_{4}: \operatorname{Pr}$ and $\mathrm{Gd}_{3} \mathrm{Ga}_{5} \mathrm{O}_{12}: \operatorname{Pr}$ under high hydrostatic pressure [23, 24].

The structural disordering in the LuAG:Pr samples under study in the different crystalline forms can be estimated based on the fragment of NP, SC and SCF emission spectra in the 475-525 nm range (Fig.2) recorded at the same experimental conditions (the excitation energy in the 7.11-7.55 eV range at the main excitonic peaks and the same intrinsic/extrinsic slits at monochromators). As can be seen from Fig.2, the structural perfection of SCFs, connected mainly with the absence of $\mathrm{Lu}_{\mathrm{Al}}$ antisite defects and low content of vacancy type defects is significantly better than that in their SC and NP counterparts. In the last samples, due to very large content of ADs and other imperfections, the significant bordering of the luminescence bands, proportional to the respective $\Delta \lambda$ values, is observed (Fig.2). On the contrary,

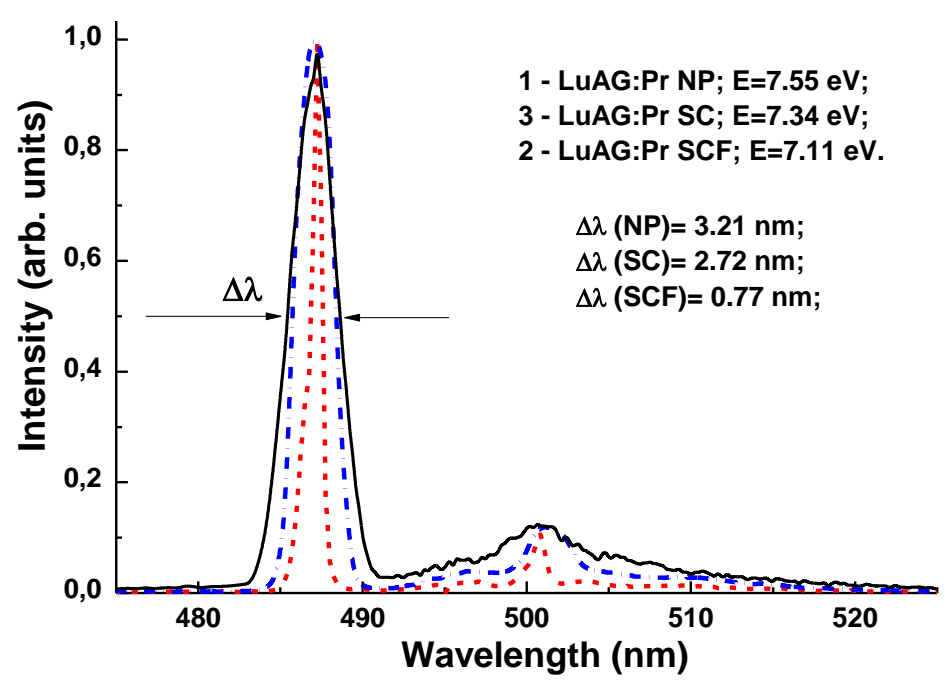

Fig.2. Fragment of normalized luminescence spectra of LuAG:Pr NP (1), SC (2) and SCF (3) samples in the $475-525 \mathrm{~nm}$ range, recorded at the same experimental conditions at $10 \mathrm{~K}$. The $\Delta \lambda$ values indicate the FWHM of $\mathrm{f}-\mathrm{f}$ emission band at $487.3 \mathrm{~nm}$. 
the emission lines related to the f-f transition of $\operatorname{Pr}^{3+}$ ions are extremely narrow in the SCF sample. This shows the substantial importance of involvement of the SCF samples to the investigation not only the nature of intrinsic luminescence of complex oxide compounds, but also the energy structure of rare-earth ions in them as well.

3.2 Excitation spectra. The excitation spectra of the $\operatorname{Pr}^{3+}$ d-f luminescence in LuAG:Pr NP, SC and SCF, registered at $320 \mathrm{~nm}$ in the different time intervals, are presented in Fig.3, a-c, respectively. In the transmittance range of LuAG host (3.7-6.5 eV) these spectra consist of two strong doublet bands with peaks at 4.35-4.36 and 4.65 eV and 5.13-5.15 and 5.34-5.35 eV, related to $4 \mathrm{f}-5 \mathrm{~d}\left(\mathrm{E}_{1}\right.$ and $\left.\mathrm{E}_{2}\right)$ transitions of $\operatorname{Pr}^{3+}$ ions, as well as the unresolved band peaked at $6.15-6.37 \mathrm{eV}$, most probably corresponding to the $4 \mathrm{f}-5 \mathrm{~d}\left(\mathrm{~T}_{2 \mathrm{~g}}\right)$ transitions of $\operatorname{Pr}^{3+}$ ions. The structure of the mentioned doublet bands was attributed in [18] to the transitions between ${ }^{3} \mathrm{H}_{4}$ ground level of $4 \mathrm{f}^{2}$ state and two low-spin (LS) and high-spin (HS) levels of $4 f-5 d\left(E_{1}\right.$ and $\left.E_{2}\right)$ bands of the $4 f 5 d$ configuration of the $\operatorname{Pr}^{3+}$ ion. Usually the excitation spectra of the $\operatorname{Pr}^{3+}$ doped LuAG SC are highly distorted in the case of relatively high Pr concentration at which the well-known phenomenon of saturation of the high intensity peaks occurs (Fig.3). For this reason, the separation of the LS and HS of $4 f 5 d\left(E_{1}\right)$ and $4 f 5 d\left(E_{2}\right)$ bands is more clearly evident in the excitation spectra of the $\operatorname{Pr}^{3+}$ luminescence in LuAG:Pr SCs and SCFs and practically is not observed in NPs (Fig.3a,b, curves 1).

Taking into account the position of the low energy excitation bands (Fig.3b) and the high-energy emission and of $\operatorname{Pr}^{3+}$ ions (Fig.1a) at $10 \mathrm{~K}$, we can also estimate the Stokes shift of the $\operatorname{Pr}^{3+}$ luminescence in LuAG:Pr host which is equal to $0.34 \mathrm{eV}$. This value is in good agreement with the data presented in [22].

The excitation spectra of the integral, fast and slow emission components of $\operatorname{Pr}^{3+}$ luminescence in LuAG:Pr NP, SC and SCF in the exciton range and at the onset of interband transitions are presented in Fig.3 a-c, respectively. The excitation of the $\operatorname{Pr}^{3+}$ luminescence is also occurs by the slow STE luminescence (in the band peaked at $250 \mathrm{~nm}$ ) in LuAG NPs and SCs in the bands peaked at 7.3 and $7.76 \mathrm{eV}[9,10,25]$ (Fig.2c, curves 1 and 3). Excitation spectra of the fast component of the $\operatorname{Pr}^{3+}$ luminescence in LuAG:Pr garnet in the 6.5-11 eV range consist of the dominant bands peaked at different energies, namely, at $7.55 \mathrm{eV}$ in NPs, at $7.34 \mathrm{eV}$ in SCF and at 7.11 eV in SCs (Fig.2a, curves 1-3, respectively). The mentioned excitation energies correspond to the energy of creation of excitons bound with isolated in $\operatorname{Pr}^{3+}$ ions in NPs and SCFs and most probably with dimer $\operatorname{Pr}^{3+}$-AD centers in SC [25]. The nature of these exciton state is considered also in $[23,24]$ where reaching this state is related to the $\operatorname{Pr}^{4+}+h_{\mathrm{vb}}$ transitions.

The bump at $6.8 \mathrm{eV}$ in the excitation spectra of the integral and slow component of the $\operatorname{Pr}^{3+}$ luminescence in LuAG:Pr SCs can correspond to the energy of creation of excitons localized around $\mathrm{Lu}_{\mathrm{Al}}$ centers emitting in the $280 \mathrm{~nm}$ band (see [9, 10, 23] for details). Excitation of this AD related emission 

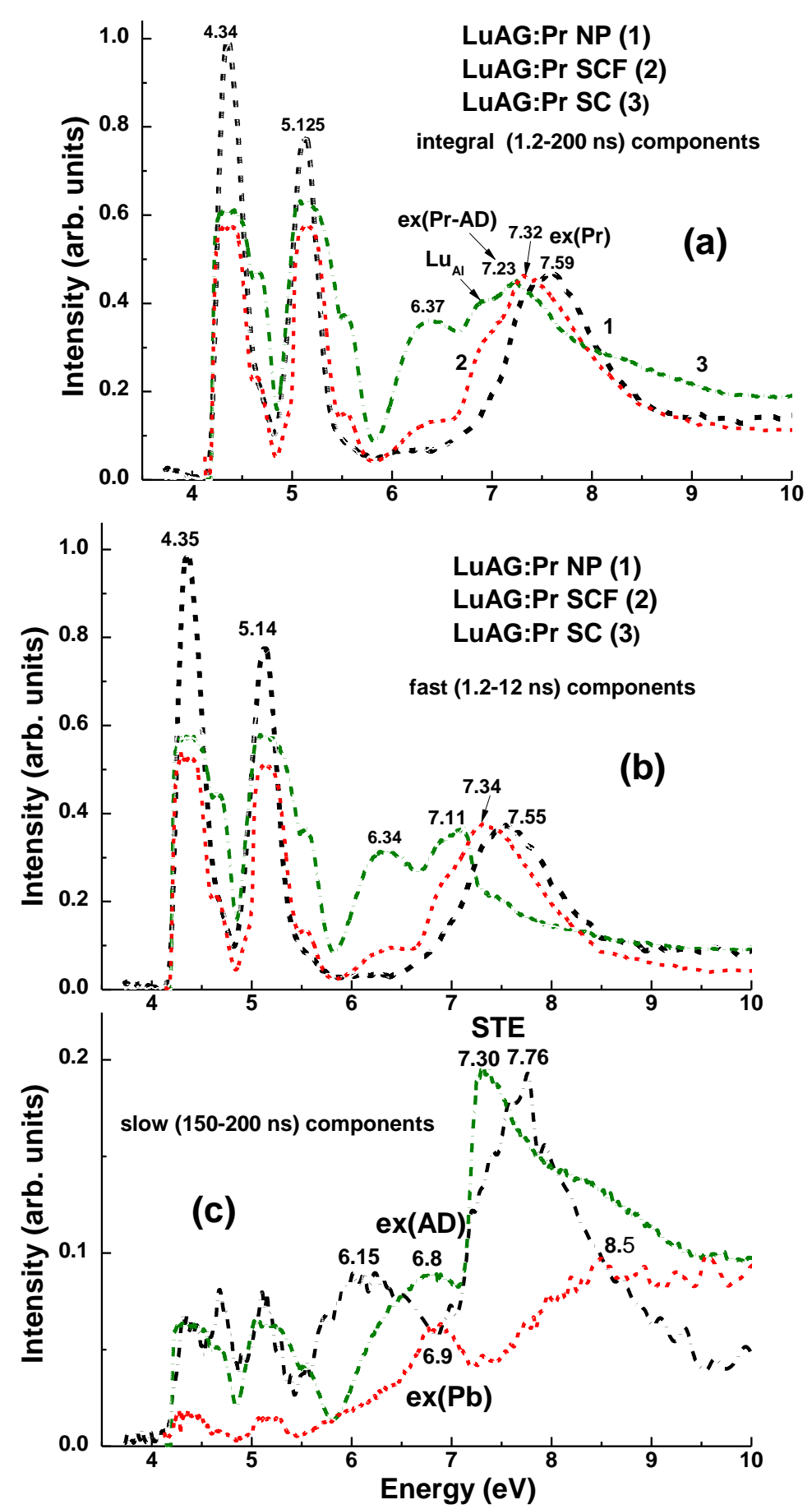

Fig.3 Excitation spectra of integral (a), fast (b) and slow (b) components of $\operatorname{Pr}^{3+}$ d-f luminescence at $360 \mathrm{~nm}$ in LuAG:Pr NP (1), SCF (2) and SC (3) at $10 \mathrm{~K}$.

band, located in the range of the $4 \mathrm{f} 5 \mathrm{~d}\left(\mathrm{E}_{1}\right) \operatorname{Pr}^{3+}$ absorption band, results also in the excitation of the $\operatorname{Pr}^{3+}$ luminescence. Due to the relatively slow emission of $\mathrm{AD}$ centers with decay time in the hundred ns range $[9,10,25]$, such process causes also the large content of slow component in the $\operatorname{Pr}^{3+}$ luminescence (Fig.2c, curve 3). The bump at $6.89 \mathrm{eV}$ in the excitation spectra of LuAG:Pr SCFs (Fig.4a, curve 1) most probably has another nature and can relate to the creation of excitons localized around $\mathrm{Pb}^{2+}$ centers [26]. As opposed to SCs and SCFs, this bump is fully absent in the excitation spectra of LuAG:Pr NP. It is also important to note here that intensity of slow component of the $\mathrm{Pr}^{3+}$ luminescence is 
significantly (by one order of magnitude) lower in the LuAG:Pr SCFs (Fig.2c, curve 2) than that in their NP and SC counterpart (Fig.2c, curves 1,2, respectively).

Therefore, the notable differences are observed in the excitation spectra of LuAG:Pr NPs, SCFs and SCs which are caused by the involvement of $\mathrm{Lu}_{\mathrm{Al}} \mathrm{ADs}$ in SCs and $\mathrm{Pb}^{2+}$ flux related dopants in SCFs in the excitation processes of the $\operatorname{Pr}^{3+}$ luminescence and such influence is practically fully absent in the excitation spectra of NP counterpart. Namely, we have observed the 0.44 and $0.2 \mathrm{eV}$ differences in the energies of creation of excitons bound with the isolated $\mathrm{Pr}^{3+}$ ions in LuAG:Pr NP (Fig. 2b, curve 1) and most probably dipole $\mathrm{Pr}-\mathrm{Pb}$ and $\mathrm{Pr}-\mathrm{Lu}_{\mathrm{Al}} \mathrm{AD}$ centers in the SCF and SC counterparts (Fig.2b, curves 2 and 3, respectively). Based on the excitation spectra of LuAG:Pr NP, SCFs and SCs we can also estimate more exactly the relative positions of the $\operatorname{Pr}^{3+} 5 \mathrm{~d}$ levels in LuAG band structure and positions of the defect centers as well.

3.3 Decay kinetics. The comparison of the luminescence decay kinetics of LuAG:Pr NPs, SCFs and SCs is presented in Fig. 4 at $300 \mathrm{~K}$. Under excitation in the intrinsic $\operatorname{Pr}^{3+}$ excitation bands at 4.5 and $5.16 \mathrm{eV}$ at $300 \mathrm{~K}$, the decay curves of the $\mathrm{Pr}^{3+}$ luminescence practically coincide with decay times of 20 , 19.2 and 18.1 ns (Fig.3, curves 1, 1', 1', respectively). At the same time, we have found the notable differences in the decay kinetics of LuAG:Pr NP, SCF and SC counterpart under excitation in the exciton range (Fig.3, curves 2, 2',2'') and high energy excitation (Fig.3, curves 3, 3', 3''). These differences are caused by participation of the ADs in $\mathrm{SCs}$ and $\mathrm{Pb}^{2+}$ flux related dopant in SCFs in the excitation processes of the $\operatorname{Pr}^{3+}$ luminescence in LuAG host as emission centers and trapping centers as well. In such a way the delivery of the excitation energy to the emission centers can be significantly delayed in LuAG:Pr SCs and lower in SCFs. Namely, due to excitation of the $\operatorname{Pr}^{3+}$ luminescence in LuAG:Pr SCs by the

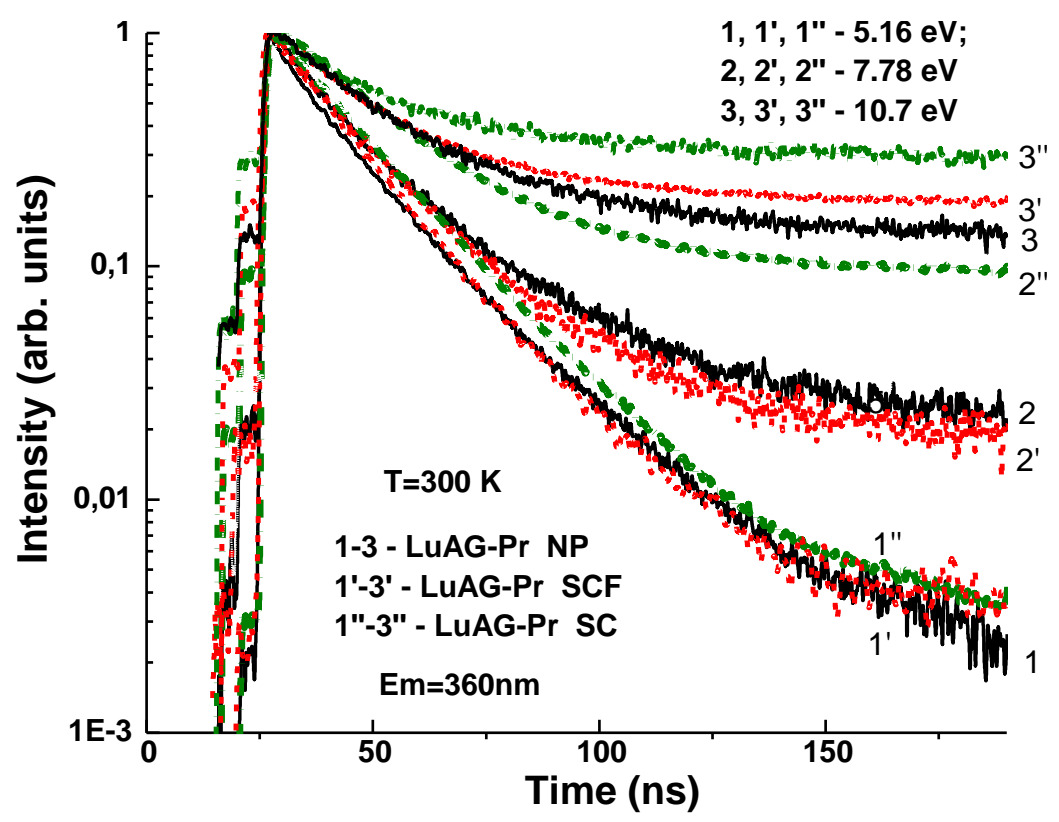

Fig.4. Comparison of the decay kinetics of $\operatorname{Pr}^{3+}$ d-f luminescence of LuAG:Pr NP (1-3), SCF (1'3') and SC (1' '-3',) at $300 \mathrm{~K}$ under excitation in $\operatorname{Pr}^{3+}$ absorption band at $5.16 \mathrm{eV}(1,1$ ', 1',), exciton range at $7.78 \mathrm{eV}\left(2,2^{\prime}, 2^{\prime \prime}\right)$ and in the range of interband transitions at $10.7 \mathrm{eV}(3,3,3$ '’). 
emission of $\mathrm{Lu}_{\mathrm{Al}} \mathrm{AD}$ related centers (Fig.2, curves 3) as well as the temporal localization of charge carriers at these centers [27], the decay kinetics of the $\operatorname{Pr}^{3+}$ luminescence in SCs is significantly slower (Fig.3, curves 2"' and 3') than that in NP and SCF analogues (Fig.3, curves 2, 2' and 3, 3'). On the contrary, under excitation in the range of interband transitions and exciton range, the decay kinetics of the $\operatorname{Pr}^{3+}$ luminescence in LuAG:Pr NPs and SCFs is significantly faster at $300 \mathrm{~K}$ (Fig.3, curves 2, 2' and 3, 3') due to the absence of $\mathrm{Lu}_{\mathrm{Al}}$ ADs and lower concentration of oxygen vacancies. Specifically, under highenergy excitation $(10.75 \mathrm{eV})$ the average decay time of the $\operatorname{Pr}^{3+}$ luminescence in LuAG:Pr NPs, SCFs and SCs at $300 \mathrm{~K}$ is equal to $39,46.5$ and $68 \mathrm{~ns}$, respectively.

We have also estimated the content of the slow components in the decay of the LuAG:Pr NPs, SCs and SCFs under high-energy $(10.7 \mathrm{eV})$ excitation, using the ratio between intensity $\mathrm{I}_{\mathrm{s}}$ of the decay components which is slower than the repetition frequency of SR (200 ns) and the decay amplitude $I_{t}$ of the rising part of the decay curve as $\mathrm{K}_{\mathrm{s}}=\left[\mathrm{I}_{\mathrm{s}} / \mathrm{I}_{\mathrm{t}}\right]^{*} 100 \%$ (Fig.4). The content of slow components is significantly larger in LuAG:Pr SCs (32.5\%) than that in SCFs (18.2\%) and NPs (14.1\%) (see Fig.4). The main reason for such a slowing-down of the decay of the $\mathrm{Ce}^{3+}$ luminescence and an increase of the amount of slow emission components in LuAG:Pr SC, grown at high temperature in reducing atmosphere is presence of the large content of $\mathrm{Lu}_{\mathrm{Al}} \mathrm{AD}$ and oxygen vacancies as emission and trapping centers in comparison with the condition of low-temperature crystallization of NPs and SCFs from the low temperature sintering procedure and LPE growth from melt-solution in air.

\section{Conclusions}

Comparison of the luminescent properties of LuAG:Pr nanopowders (NPs), sintering by the Pechini method, single crystals (SCs), grown from the high temperature melt by HDC method, and single crystalline films (SCFs) grown by low temperature LPE method from PbO based flux, was performed using the time-resolved emission spectroscopy of under excitation by synchrotron radiation with an energy of 3.7-25 eV at $300 \mathrm{~K}$ and $10 \mathrm{~K}$.

Based on the obtained results, we have more exactly determined the energy structure of the $\operatorname{Pr}^{3+}$ ions and defect centers in LuAG host. We have found the notable differences in the $\operatorname{Pr}^{3+}$ emission and excitation spectra as well as the luminescence decay kinetics in LuAG:Pr NP and SCF or SC counterparts caused by involving the $\mathrm{Lu}_{\mathrm{Al}}$ antisite defects (AD) and oxygen vacancies in $\mathrm{SC}$ and $\mathrm{Pb}^{2+}$ flux related dopant in SCFs in the excitation processes of the $\operatorname{Pr}^{3+}$ luminescence in these crystalline forms of the LuAG garnet. The influence of host defects on the $\operatorname{Pr}^{3+}$ luminescence is significantly smaller in the LuAG:Pr NPs. We have also estimated the differences in the energies of creation of excitons bound with the isolated $\operatorname{Pr}^{3+}$ ions in LuAG:Pr NP and dipole $\mathrm{Pr}-\mathrm{Lu}_{\mathrm{Al}} \mathrm{AD}$ and $\mathrm{Pr}-\mathrm{Pb}$ centers in the SC and SCF counterparts.

We have also found that under excitation in the range of interband transitions and exciton range, the decay kinetics of the $\operatorname{Pr}^{3+}$ luminescence in LuAG:Pr NP and SCF is significantly faster and the con- 
tent of slow emission component is significantly smaller than that in LuAP:Pr SC counterpart due to the absence of $\mathrm{Lu}_{\mathrm{Al}} \mathrm{ADs}$ and lower concentration of oxygen vacancies.

\section{Acknowledgements}

This work was realized within the Polish NCN 2012/07/B/ST5/02376 and NCBR NANOLUX \#286 projects and partly also in the frame of Ukrainian FK 64/34-16 and SL-20F projects. The investigation at the Superlumi station (HASYLAB, DESY) were performed within I-20110938 EC project.

\section{References}

[1] H. Ogino, A. Yoshikawa, M. Nikl, A. Krasnikov, K. Kamada, T. Fukuda, Journal of Crystal Growth, 287 (2006) 335.

[2] H. Ogino, A. Yoshikawa, M. Nikl, K. Kamada, T. Fukuda, Journal of Crystal Growth 292 (2006) 239.

[3] J. Pejchal, M. Nikl, E. Mihokova, J. A. Mares, A. Yoshikawa, H. Ogino, K. M. Schillemat, A. Krasnikov, A. Vedda, K. Nejezchleb, Journal of Physics D. Applied Physics, 42 (2009) 10.

[4] Yu. Zorenko, V. Gorbenko, T. Voznyak, T. Martin, P.-A. Douissard, J.A. Mares, M. Nikl. Proc. SPIE, 7310 (2009) 731007.

[5] T. Yanagida, Y. Fujimoto, K. Kamada, D. Totsuka, H. Yagi, T. Yanagitani, Y. Futami, S. Yanagida, S. Kurosawa, Y. Yokota, A. Yoshikawa, M. Nikl, IEEE Transactions on Nuclear Science, 59 (2012) 2146.

[7] J. A. Mares, Y. Shi, M. Nikl, Y. Shen, Y. Pan, and X. Feng, 11th Europhysical Conference on Defects in Insulating Materials (Eurodim 2010), 5 (2010) 6.

[7] Y. Shen, Y. Shi, X. Feng, Y. Pan, J. Li, Y. Zeng, et al., "The Harmful Effects of Sintering Aids in Pr:LuAG Optical Ceramic Scintillator," Journal of the American Ceramic Society, vol. 95, pp. 2130 - 2132, 2012.

[8] Y. Shen, X. Feng, V. Babin, M. Nikl, A. Vedda, F. Moretti, , et al. , "Fabrication and scintillation properties of highly transparent Pr:LuAG ceramics using Sc,La - based isovalent sintering aids," Ceramics International, vol. 39, pp. 5985-5990, 2013.

[9] Yu. Zorenko, A. Voloshinovskii, V. Savchyn, T. Vozniak, M. Nikl, K. Nejezchleb, V. Mikhailin, V. Kolobanov, D. Spassky. Phys. Stat. Sol. (b). 244 (2007) 2180.

[10] Yu. Zorenko, V. Gorbenko, I. Konstankevych, A. Voloshinovskii, G. Stryganyuk, V. Mikhailin, V. Kolobanov, D. Spassky. J. Luminescence 114 (2005) 85.

[11] Yu. Zorenko, V. Gorbenko, A. Voloshinovskii, V. Vistovskii, M. Nikl, E. Mihokova, K. Nejezchleb. IEEE Transaction on Nuclear Science 55 (2008) 1186.

[12] Yu. Zorenko, V. Gorbenko, T. Voznyak, V. Mikhailin, V. Kolobanov, D. Spassky, M. Nikl. IEEE Transaction on Nuclear Science 55 (2008) 1192. 
[13] Yu. Zorenko, T. Zorenko, T. Voznyak, O. Sidletskiy, Journal of Luminescence, 137 (2013) 204.

[14] Yu. Zorenko, V. Gorbenko, V. Savchyn, T. Voznyak, V.V. Gorbenko, B. Grinyov, O. Sidletskiy, D. Kurtsev, A. Fedorov, V. Baumer, M. Nikl, J.A. Mares, A. Beitlerova, Optical Materials, 34 (2012) 1969.

[15] W. Drozdowski, P. Dorenbos, R. Drozdowska, A. J. J. Bos, N. R. J. Poolton, M. Tonelli, M. Alshourbagyet, IEEE Transactions on Nuclear Science, 56 (2009) 320.

[16] Y. Shi, M. Nikl, X. Feng, J. A. Mares, Y. Shen, A. Beitlerova, et al., Journal of Applied Physics, vol. 109, 2011.

[17] J.M. Ogiegło, A. Zych, T. Jüstel, A. Meijerink, C.R. Ronda, Optical Materials, 35 (2013) 322.

[18] A. Wojtowicz, K. Brylew, M. Witkowski, W. Drozdowski, K. Kamada, T. Yanagida, A. Yoshikawa, Hasylab Annual Report 2 (2012) http://photon-science.desy.de/annual_report/files/ 2012/20122553.pdf.

[19] V. Gorbenko, Yu. Zorenko, V. Savchyn, T. Zorenko, T. Zorenko, A. Pedan, V. Shkliarskyi, Radiation Measurements, 45 (2010) 461.

[20] V. Babin, V. Gorbenko, A. Krasnikov, A. Makhov, M. Nikl, S. Zazubovich, Yu. Zorenko. Radiation measurements, 45 (2010) 415.

[21] S.V. Nizhankovsky, A.Ya. Dan'ko, Yu.V. Zorenko, V.V. Baranov, L.A. Grin', V.F. Tkachenko and P.V. Mateichenko. Physics of the Solid State, 53 (2011) 127.

[22] K. Ivanovskikh, J.M. Ogiegło, A. Zych, C.R. Ronda, A. Meijerink, ECS Journal of Solid State Science and Technology, 2 (2013) R3148.

[23] Cz. Koepke, K. Wisniewski, D. Dyl, M. Grinberg, M. Malinowski,Optical Materials 28 (2006) 137.

[24] M. Grinberg, Optical Materials 35 (2013) 2006.

[25] Y. Zorenko, V. Gorbenko, E. Mihokova, M. Nikl, K. Nejezchleb, A. Vedda, V. Kolobanov, D. Spassky. Radiation Measurements, 42 (2007) 521.

[26] Yu. Zorenko, T. Voznyak, V. Gorbenko, T. Zorenko, A. Voloshinovski, V. Vistovsky, M. Nikl, K. Nejezchleb, V. Kolobanov and D. Spasski, Optics and Spectroscopy 104 (2008) 75.

[27] M. Nikl, J. Pejchal, E. Mihokova, E., J.A. Mares, H. Ogino, A. Yoshikawa, T. Fukuda, A. Vedda, C. D’Ambrosio, Applied Physics Letters 88 (2006) 41916. 